\title{
O CONSUMO DE SUBSTÂNCIAS PSICOATIVAS E O AUTOCUIDADO ENTRE PESSOAS EM SITUAÇÃO DE RUA NA CIDADE DE JUAZEIRO-BA
}

\author{
Geisabel Lima Silveira \\ Graduada em Psicologia pela \\ Universidade Federal do Vale do \\ São Francisco \\ Luzania Barreto Rodrigues \\ Antropóloga. Professora adjunta III \\ do colegiado de Ciências Sociais da \\ Universidade Federal do Vale do \\ São Francisco
}

\begin{abstract}
Resumo
A parcela da população que está em situação de rua e faz uso de substâncias psicoativas encontra-se em condição de vida vulnerável e precária, à margem do sistema e desassistidos pelos serviços e políticas públicas de saúde. Nesta pesquisa, buscou-se compreender como o cuidado e os riscos à saúde perpassam estes cenários. Explorar práticas de autocuidado em saúde nestes contextos, além de relevante, revela-se como um grande desafio posto, atualmente, aos profissionais da área de saúde. Esta pesquisa é de cunho qualitativo e foi realizada em duas regiões do centro da cidade de Juazeiro-Bahia e teve como suporte teórico para análise dos resultados os conceitos de cuidado e autocuidado e a antropologia interpretativa de Clifford Geertz. Este estudo identificou padrões de "uso compulsivo" das substâncias psicoativas crack e álcool. Percebeu-se que os contextos e formas de utilização de SPA estão oferecendo riscos diretos e indiretos à saúde da população pesquisada. Forjaram-se nestes contextos esboços de estratégias de autocuidado com a saúde a partir das experiências dos sujeitos. Evidenciou-se a necessidade de maior aproximação desses contextos e criação de políticas de atenção à saúde voltadas para este público.
\end{abstract}

Palavras Chave: Autocuidado; Psicologia; Usuário de substâncias psicoativas; População em situação de rua.

\section{THE CONSUMPTION OF PSYCHOACTIVE SUBSTANCES AND SELF CARE BETWEEN PEOPLE IN STATE STREET IN TOWN JUAZEIRO-BA}

\begin{abstract}
A portion of the population is living on the streets and makes use of psychoactive substances, is in vulnerable and precarious condition life, outside of the system and underserved by services and public health policies. And this research was to understand how the care and health hazards pass over these scenarios. Exploring the selfcares practices in these contexts, besides relevant, reveals itself as a major challenge placed today, to the professionals in the health area. This is qualitative research and was accomplished in two regions of the city center of Juazeiro - Bahia having, as a guiding methodology for analyzing the results, to the concepts of care and self-care and the interpretive anthropology of Clifford Geertz. This study identified patterns of "compulsive use" of psychoactive substances crack cocaine and alcohol. It was perceived that the forms and contexts of use of SPA are offering direct and indirect risks to the health of this population. Forged in these contexts outlines strategies for self-care to health from the experiences of the subjects. It was revealed the need for greater approach to these contexts and creating health care policies aimed at this audience.
\end{abstract}

Keywords: Self-care; Psychology; Psychoactive substances users; The homeless population. 


\section{INTRODUÇÃO}

Ao observar o cenário da atenção à saúde, voltado para pessoas que fazem uso de substâncias psicoativas (SPA), na região do Vale do São Francisco, emergem algumas dúvidas: Os "usuários" de substâncias psicoativas que se encontram em situação de rua e não são acessados por nenhum tipo de dispositivo de saúde, dispensam algum modo de cuidado à sua saúde? Será que nestes cenários existem práticas que podem ser consideradas como “cuidado em saúde"? A preocupação com o cuidado com a saúde e os modos de uso das SPA podem ser observados nestes contextos? As modalidades de uso de substâncias psicoativas estão expondo os usuários a riscos diretos (ou adicionais) à saúde?

Destas inquietações emerge o interesse por investigar as nuances do uso de psicoativos entre a população em situação de rua, apreendendo, na medida do possível, como o cuidado com a saúde perpassa estes contextos, partindo principalmente da perspectiva dos próprios sujeitos. Porém, para se compreender como o cuidado pode estar atravessando estes cenários, mostra-se necessário que anteriormente se compreenda como os riscos se apresentam nesse meio.

Ao pensar a utilização de substâncias psicoativas entre pessoas em situação de rua, esta problemática se complexifica ainda mais. Atualmente, o sistema capitalista, em face do avanço da globalização e do voraz progresso tecnológico, tem ressoado, na sociedade, de forma negativa, ao reforçar o fosso das desigualdades sociais. Disso resulta a exclusão socioeconômica de significativa parcela da população, posta à margem do ciclo da "máquina" do consumo, cada vez mais competitivo e exigente, que, muitas vezes, tem como resultado a "imposição" de condição de vida de extrema vulnerabilidade social a "grandes minorias". (1)

O contexto de rua tem sido os espaços utilizados por essa parcela da população com inúmeras finalidades: moradia, repouso, trabalho e também de uso de substâncias psicoativas. Suas explicações para o uso abusivo de SPA nesses contextos flutuam: ora decorrem do fato de estar na rua, ora são fatores que influenciam a passagem para estes contextos. ${ }^{(2)}$

As pessoas em situação de rua são, em sua maioria, também fazem uso de psicoativos, por isso, duplamente estigmatizadas, tanto pela condição de estar vivendo nos espaços de rua, quanto pelo uso de SPA consideradas ilícitas. É relevante pensar o cuidado destes sujeitos, que geralmente encontram-se estigmatizados e discriminados pela sociedade, uma vez que 
estes são reforçados inclusive pelos dispositivos de saúde ao colocar esta população à margem destes serviços.

Para compreender o uso de SPA, é importante partir do pressuposto de que não é a substância em si que determina o consumo, mas a relação entre sujeito, substância e contexto socioeconômico e cultural. Sendo assim, para se compreender o uso de substância psicoativa (inclusive seus riscos) faz-se necessário primordialmente entender as relações estabelecidas entre os sujeitos e as substâncias, considerando-se três aspectos: a "droga em si" (o efeito farmacológico produzido), o "set" (as circunstâncias do sujeito durante o uso) e o "setting" (meio social em quase faz o uso). ${ }^{(3)}$ Estes três elementos juntos formam o consumo, mas é necessário compreender que é o sujeito que prevalece nesta relação, e não a SPA como se costuma tratar.

O meio sociocultural (setting) que favorece o uso de SPA sob um padrão específico, ${ }^{(4)}$ que são pautados informalmente pela criação de "sanções sociais" que se referem a determinados conjuntos de valores e normatizações. Estes regulariam as modalidades como as substâncias específicas serão consumidas num dado grupo, e os "ritos sociais" que regulariam tipos de comportamentos normatizados em face de dada SPA.

Isso demonstra a relevância de se identificar as modalidades de usos de SPA dentro do contexto da população em situação de rua, pois essas são construídas num emaranhado complexo de relações e significados. Deste modo, ao buscar conhecer os riscos à saúde, devese apreciar, anteriormente, as formulações sociais que são feitas em torno do uso. É necessário um olhar contextualizado dos modos de consumo de SPA para se pensar como práticas de autocuidado em saúde podem ser articuladas a estes usos, que não desconsiderem o sentido que os sujeitos tecem sobre sua prática.

Atentar para os fatores psicossociais, tais como a substância e a quantidade utilizada, atributos intrínsecos "usuário", o imaginário acerca dos efeitos produzidos e o contextos em que ocorrem, ${ }^{(4)}$ retira-se o foco das propriedades farmacológicas e amplia a complexidade do fenômeno do uso de SPA entrelaçada a um contexto sociocultural que influencia, inclusive, nos efeitos que as substâncias psicoativas produzem nos seus consumidores. Sendo assim, compreender os usos de SPA exige uma apreensão de uma estrutura maior e mais complexa que circunscreve estas práticas, principalmente quando se almeja a construção de estratégias de autocuidado com saúde. 
A literatura demarca a diferenciação entre práticas "leves" e "pesadas" de uso de SPA, ${ }^{(4)}$ sendo as 'pesadas' caracterizadas pelo uso imoderado, 'violento', de algumas substâncias, que algumas vezes levam ao isolamento; diferente das práticas 'leves', que são, via de regra, realizadas em contextos coletivos e aqueles que utilizam a SPA procuram estar sob controle, inclusive percebendo os efeitos que vão sendo produzidos.

Isso reforça que os sujeitos podem estabelecer diferentes práticas de uso de SPA. Sendo o uso de SPA uma relação que o sujeito estabelece, mostra-se necessário construir com estes indivíduos as possibilidades de uso menos arriscados e abusivos de drogas, a fim de minorar os danos e riscos à saúde. Tais estratégias devem estar concatenadas com a realidade das práticas de uso, ou seja, é necessário conhecer as substâncias psicoativas utilizadas, as formas como são utilizadas, os contextos onde são utilizados, e como os riscos podem estar atravessando essas práticas para que, então, as estratégias de autocuidado à saúde sejam esboçadas e construídas.

Articula-se aqui noção de cuidado que parte de uma perspectiva ética, assumindo-o não como uma ação assistencial ou técnica à saúde, mas sim, um modo de como o ser relaciona-se consigo e com o seu entorno, em prol do bem-estar. ${ }^{(5)}$ Tais noções podem ser articuladas com a Política de Redução de Danos, a qual tem por princípio potencializar estratégias que minimizem os danos à saúde em decorrência do uso de SPA, como uma via pela qual o autocuidado, enquanto atitude ética, pode se inserir nos contextos e modos de uso de substâncias psicoativas, não apenas como tendência técnica, mas também por uma atitude ética e política.

Deste modo, sendo o aparato de assistência à saúde precariamente acessível (ou mesmo inacessível) às pessoas que estão em situação de rua, pensar práticas de cuidado pautadas pela redução de danos, tendo em vista que esta pressupõe a criação de estratégias de autocuidado que os sujeitos possam vir a criar e/ou incorporar ao uso de SPA, revela-se como uma relevante contribuição para esta população.

Visto isso, este estudo propõe-se a investigar como os modos de uso de SPA entre pessoas em situação de rua na cidade de Juazeiro-BA, em alguma medida, oferecem riscos diretos, ou indiretos, à saúde desta população. E, partindo disso, vislumbrar que estratégias de cuidado com a saúde podem ser pensadas no próprio contexto de rua, que possam vir a minorar os riscos à saúde da população em situação de rua que faz uso de SPA. Podem-se forjar, inclusive, estratégias de ações articuladas com os dispositivos de saúde do Sistema 
Único de Saúde (SUS), mas este trabalho busca observar as formas de cuidado com a saúde que existem nestes contextos, sinalizando possíveis ações que possam evitar ou minimizar os danos à saúde em razão das modalidades de uso de SPA em cenários como este.

\section{FUNDAMENTAÇÃO TEÓRICA}

A população em situação de rua, incluindo-se a parcela que faz uso de substâncias psicoativas (SPA), encontra extrema vulnerabilidade e escassez de informações para despender atenção e cuidado com a saúde, sendo, inclusive, desassistidos pelos serviços do Sistema Único de Saúde (SUS). E, como afirma Oliveira ${ }^{(6)}$ fomentar a "cultura de autocuidado" representa além de um grande desafio aos profissionais de saúde, um recurso estratégico para sugerir mudanças nos hábitos, possíveis de ser praticados pelos sujeitos, visando cuidado à sua própria saúde.

Autocuidado refere-se ao manejo de atos para consigo ou com o contexto, seguindo os interesses do próprio sujeito, cujo objetivo é a busca do bem-estar e de uma vida saudável. Por práticas de autocuidado entende-se o conjunto de comportamentos, ações intencionais em benefício próprio, com vista a manutenção ou melhoraria da "vida, saúde e o bem-estar", que perpassa pela iniciativa do sujeito em buscar formas para garantia da qualidade da saúde e do desenvolvimento. ${ }^{(7)}$

A abordagem da Redução de Danos fomenta e efetiva ações essenciais de autocuidado, com vistas a minimizar os riscos a saúde, ${ }^{(8)}$ Isto porque esta abordagem constitui-se de uma série de práticas cuja finalidade é minimizar as consequências danosas decorrentes do uso abusivo de SPA, lícitas e ilícitas, a partir de estratégias práticas que próprios sujeitos possam utilizar em seu cotidiano, construídas com referência em suas experiências e interesses pessoais.

A perspectiva da Redução de Danos (RD) considera a relevância de entender a complexidade que permeia o fenômeno da utilização de SPA, desde as diferentes modalidades de uso, às peculiaridades dos sujeitos e das culturas nas quais estão inseridos. Partindo do contexto sociocultural e econômico, os profissionais que trabalham sob a ótica da Redução de Danos procuram compreender a hierarquia dos riscos que atravessam as práticas de uso das SPA, de modo que as estratégias de autocuidado construídas contemplem a singularidade da pessoa, do contexto, suas práticas e seus interesses. 
Isto não implica pura, e simplesmente, em teorias e metodologias práticas. A RD exige dos profissionais novos olhares, e percepções mais sensíveis a especificidades do fenômeno do uso de psicoativos, que leve em consideração as experiências, os saberes, e os desejos do sujeito. Sendo assim, visa favorecer a participação deste no seu processo de autocuidado, ou seja, trata-se de produzir práxis efetivamente pautada no/para sujeitos e nas potências da sua existência. ${ }^{(9)}$

As estratégias de Redução de Danos favorecem que o sujeito crie outras formas de singularização da sua vivência e seus modos de relação com o uso de SPA, e potencializa um maior cuidado de si, ou seja, uma ocupação/preocupação consigo no que tange a própria saúde e bem estar. ${ }^{(10)}$ Sendo assim, a RD revela-se como uma abordagem que auxilia os sujeitos - oferecendo-lhe modalidades de intervenções flexíveis e contextualizadas - a assumirem o cuidado com a própria saúde.

A Redução de Danos é contrária ao modelo preventivo tradicional, que não leva em consideração que existem diferentes práticas de uso (umas menos saudáveis que outras) e acabam impondo um objetivo hegemônico de abstenção do uso, que desconsidera as peculiaridades dos sujeitos, diferente deste que busca desenvolver juntamente com os "usuários" estratégias com que possam melhorar o seu bem-estar físico e social. ${ }^{(1)} \mathrm{O}$ desafio constante da prática profissional tem sido criar intervenções que possam singularizar o sujeito, resgatando, por via dos espaços de escuta, o que há de particular e inédito para cada um. E, assim, possibilitar que cada pessoa perceba o seu movimento e possa reposicionar-se diante disso, construindo novas possibilidades de cuidar da própria saúde e relacionar-se com a SPA de modo singular, é o desafio de a individualidade de "cada um" seja resguardada nos espaços de "todos". (12)

No Brasil, o processo de Reforma Psiquiátrica ${ }^{(13)}$ abre o movimento em defesa da reorientação epistemológica, política e cultural dos modelos assistenciais em Saúde Mental. A partir daí estruturam-se dispositivos de saúde substitutivos aos asilares e manicomiais, com serviços e estratégias de ações abertas. Nestes, inseriram-se também pessoas com transtornos decorrentes do uso de Substâncias Psicoativas, com a criação do Centro de Atenção Psicossocial para usuários de Álcool e outras Drogas - por meio da Política do Ministério da Saúde de Atenção Integral a Usuários de Álcool e Outras Drogas ${ }^{(14)}$ - na qual há o reconhecimento dos poderes públicos para o fenômeno do uso abusivo de psicoativos enquanto uma questão de saúde pública. 
O Sistema Único de Saúde define o Centro de Atenção Psicossocial para Álcool e outras Drogas como um dos principais serviços de assistência à saúde para pessoas que usam Substâncias Psicoativas, disponibilizados através do Sistema Único de Saúde. ${ }^{(8)}$ Além de norteado pela Redução de Danos, os profissionais inseridos neste dispositivo devem buscar construir uma nova lógica terapêutica, visando o resgate da cidadania e autonomia dos sujeitos.

Nota-se que os princípios da redução de danos norteiam profissionais e "usuários" a construírem práticas de autocuidado, de modo que o profissional dê voz e auxilie o sujeito na construção de suas estratégias, evidencie a singularidade, o protagonismo, a responsabilização e a autonomia do sujeito frente a seu próprio processo de cuidado. Nesse sentido, busca-se construir novos possíveis, novos modos de cuidado consoantes com o desejo, as potencialidades e o contexto dos sujeitos e dos profissionais de saúde, e esta interação requer, minimamente, implicação e respeito.

Porém, ainda assim, a parcela da população que vive em contexto de rua, ou seja, não territorializados, segundo os protocolos assistenciais dos serviço de saúde brasileiros, ficam à margem, sem acesso, literalmente descobertos por estes dispositivos. Isto revela que a saúde pública brasileira tem esbarrado nos desafios impostos pela limitação das suas políticas de atenção aos "usuários" de SPA, no que tange ao acesso às populações que se encontram em situação de rua. Os serviços criados com referência territorializada, que exigem que o sujeito tenha moradia fixa para acessar os dispositivos, exclui toda essa parcela populacional que habita os espaços de rua, evidencia-se a carência de ações e políticas alternativas que os insiram nos serviços de saúde. ${ }^{(6)}$

É notória a necessidade de reorientação dos serviços para que, em consonância com os princípios do SUS, possam criar estratégias para acessar esta população. ${ }^{(6)}$ Uma alternativa, no Brasil, foi a construção dos Consultórios de Rua do SUS, baseados em experiências exitosas na implantação de projetos de RD, que surgiram como uma forma de estimular práticas de autocuidado e oferecer cuidados especializados em saúde a pessoas que se encontram em contextos de rua e que, não são acessados (ou não têm acesso) aos demais dispositivos de saúde.

A marca dessa proposta é ofertar serviços de cuidado à saúde a pessoas que fazem uso de SPA, nos próprios cenários de rua, respeitando e levando em consideração este contexto sociocultural no qual estão inseridos, explorando estratégias de autocuidado que podem ser 
desenvolvidas e adotadas pelos próprios sujeitos, bem como possibilitando, quando necessário, o acesso aos dispositivos de saúde da "rede institucionalizada".(2) Porém, os Consultórios de Rua não fazem parte da realidade da maioria das cidades brasileiras, e esta população encontra-se sem acesso ao mínimo de informação e recurso em saúde.

Este trabalho visa contribuir para que esta população seja conhecida um pouco mais em suas peculiaridades e necessidades, e que de algum modo sirva para nortear intervenções futuras nestes contextos, que são áridos, porém férteis, que exige o conhecimento de seus cenários, peculiaridades e especificidades. Exigindo uma apropriação, na medida do possível, da realidade daquelas pessoas para então vislumbrar e/ou criar, com estas, compreensões e ações de autocuidado em saúde efetivas e contextualizadas.

Em Juazeiro, Norte da Bahia, bem como em inúmeras outras cidades do país, a população em situação de rua, que faz uso de psicoativos, encontra-se desconhecida, silenciada, desassistida, negligenciada a olhos nus pelos próprios serviços de saúde. Essa população, além de atenção à saúde, precisa ser ouvida, considerada e atendida em suas demandas, uma vez que é composta por cidadãos. Desse modo, esta pesquisa teve como objetivo geral: observar o consumo de Substâncias Psicoativas entre pessoas em situação de rua no contexto na cidade de Juazeiro-BA, e em que medida este segmento se expõe a riscos diretos (ou adicionais) à saúde, decorrentes das modalidades de uso de tais substâncias. E como objetivos específicos: identificar as modalidades de usos de SPA; conhecer as possíveis práticas de autocuidado com a saúde antes, durante e depois do uso de SPA; identificar os riscos/danos à saúde associados aos modos de uso de SPA e construir a partir da perspectiva daqueles as utilizam, possíveis estratégias de autocuidado.

\section{METODOLOGIA}

O consumo de Substância Psicoativas (SPA) entre a população de rua de Juazeiro e os prováveis riscos diretos (ou adicionais) à saúde aos quais este segmento se expõe, decorrentes das modalidades de uso de tais substâncias, foram perscrutados por meio de algumas técnicas utilizadas no trabalho de campo, para a produção de etnografias, como a observação participante, as conversas informais e entrevistas, com roteiro pré-fixado, efetivadas nos contextos em que se encontram os sujeitos sociais envolvidos. 
A literatura sobre o tema versa que a etnografia é a que melhor abarca o fenômeno do uso de SPA, enquanto o trabalho de campo favorece a construção de conhecimento que brota a partir do contato com a realidade que se busca compreender. ${ }^{(15,16)}$

A observação participante consiste num método qualitativo de investigação científica, que prefigura uma imersão densa do pesquisador no cotidiano do campo de estudo, a fim de que a coleta de dados ocorra por meio desta participação constante na rotina do grupo ou organização. Ou seja, o entendimento das questões de pesquisa será construído na inserção do pesquisador na situação natural do grupo estudado. Utilizando-o quando se pretende compreender um tema e/ou problemática substancial. ${ }^{(17)}$

Tendo em vista que as entrevistas e/ou grupos de discussão centram-se nas opiniões expressas da fala dos sujeitos, a observação enfatiza os comportamentos e relações contextualizando o que é dito. Tal aporte metodológico tem sido utilizado pelos cientistas sociais na investigação de problemas, descrição de culturas e não somente para demonstrar relações entre variáveis demarcadas abstratamente. ${ }^{(18)}$ Deve-se salientar a relevância desta técnica quanto ao aspecto de que através dela pode-se captar um gama de situações ou fenômenos que não são apreendidos por meio da fala dos sujeitos, tendo em vista que a observação direta fornece elementos peculiares e "evasivos" daquele contexto, pouco acessado por outros métodos. ${ }^{(19)}$

A observação participante supõe a utilização de inúmeras técnicas, além da imersão em campo. Sendo assim, buscou também realizar diálogos informais, entrevistas e registros em diário de campo, uma vez que estes também se inserem como meio de levantamento de dados, ao buscar coletar informações contidas nos relatos verbais dos sujeitos. ${ }^{(18)}$ A entrevista não constitui uma conversa despojada de qualquer pretensão ou neutralidade, ${ }^{(16)}$ é um instrumento que objetiva subsidiar a coleta de informações que comporão um corpo de dados referentes a objetivos específicos, mas isso não implica que estas serão cristalizadas e que seu direcionamento será inflexível.

As entrevistas foram de caráter semi-estruturado, não se trata de uma entrevista livre, há um roteiro previamente elaborado, contendo alguns aspectos relevantes com o intuito de nortear as pesquisadoras. Deste modo, este tipo de entrevista visa viabilizar uma expressão mais ampla e livre dos sujeitos entrevistados, ou seja, o menos diretivo possível, com vistas a possibilitar maior e melhor expressão do sujeito. ${ }^{(18)}$ 


\section{Cenário de Pesquisa}

A imersão em campo no cotidiano da população que faz uso de SPA no contexto de rua foi realizada em regiões do centro urbano da cidade de Juazeiro-Bahia, que é utilizada por alguns grupos como local de uso de drogas, trabalho, morada e pouso. A entrada neste contexto deu-se através do projeto Ciranda de Rua, um Coletivo de Redução de Danos do Laboratório de Pesquisa Interdisciplinar sobre o Uso de Substâncias Psicoativas (LAPIS) da Universidade Federal do Vale do São Francisco (UNIVASF), que articula ensino, pesquisa e extensão, além de realizar ações referentes "educação para uso de SPA", pautadas pela Política de Redução de Danos, no qual as pesquisadoras permaneceram inseridas por seis meses, visitando as comunidades cerca de três vezes por semana.

O projeto era desenvolvido em quatro regiões do centro urbano de Juazeiro-BA (até maio de 2012, período de greve na UNIVASF que interrompeu temporariamente a ações do coletivo). Posteriormente com a retomada das atividades da universidade e volta a campo, apenas duas regiões que puderam ser acompanhadas mais sistematicamente, e nas quais foram realizada a pesquisa ora proposta.

\section{Participantes}

A amostra desta pesquisa compreendeu os sujeitos abarcados pelo coletivo de redução de danos Ciranda de Rua, num universo de cerca cinquenta pessoas com as quais se teve contato, foram realizadas oito entrevistas e as demais informações encontram-se registradas em diário de campo. Tratou-se uma amostra intencional cujo critério de seleção para participar das entrevistas foi fazer uso de substâncias psicoativas, nos contextos estudados. A participação na pesquisa se deu mediante convite feito pela pesquisadora. Apresentavam-se os objetivos da pesquisa, a metodologia utilizada, as disposições éticas e mediante o consentimento do sujeito a entrevista era realizada e gravada.

\footnotetext{
* "Cirandas de rua" é uma ação de integração articulada entre os colegiados de Psicologia e Ciências Sociais da Universidade Federal do Vale do São Francisco, coordenada pelas professoras Mariana Ribeiro de Souza e Luzania Barreto Rodrigues, que visa identificar e propor ações de promoção à saúde com, e para, usuários de SPA em contextos de rua.
} 


\section{Instrumentos Utilizados}

Como instrumentos desta pesquisa foram utilizados gravador de voz, diário de campo e roteiro de entrevista semiestruturado. No diário de campo, as pesquisadoras fizeram registros, descrevendo os acontecimentos passados no campo, alimentado também com impressões, sentimentos, angústias e inquietações. Desde o primeiro até o último contato com o campo, as pesquisadoras mantiveram suas anotações, pois estas serviram de subsídio para descrição e análise do objeto de estudo.

As entrevistas foram semi-estruturadas, ou seja, houve um pequeno roteiro de entrevista que foi construído pela pesquisadora após um período de um mês e meio de observação participante e conversas informais. Neste roteiro constavam alguns aspectos fundamentais, que o percurso de observação participante mostrou relevante para a exploração. Tal delineamento tornou o instrumento flexível para que novas questões pudessem ser formuladas no decorrer da sua realização, bem como para que os entrevistados tivessem a possibilidade de se expressarem de forma mais livre.

As entrevistas foram realizadas nos próprios contextos de rua, em que o coletivo de redução de danos Ciranda de Rua desenvolvia suas atividades. Convidava-se o participante a colaborar com a pesquisa, explicando seus objetivos e finalidades, realizando-se os devidos esclarecimentos exigidos nas questões éticas do trabalho. Ao concordar e autorizar sua participação, procurava-se um local adequado para captação do som. Neste momento, iniciava-se gravação de áudio. As entrevistas foram posteriormente transcritas e analisadas pelas pesquisadoras.

O fluxo constante e imprevisível da população pesquisada dificultou a realização das entrevistas. O mínimo de vinculação com os sujeitos mostrou-se necessário para que os mesmos se dispusessem realizar a entrevista, porém a alta rotatividade prejudicava que as pessoas fossem encontradas para esta abordagem. Além disso, muitos que já tinham vínculo com as pesquisadoras e com o grupo não aceitaram realizar a entrevista, tais negativas podem ser atribuídas à ilicitude da prática e o temor de delação. Deste modo, o diário de campo, além de contextualizar a entrevistas realizadas, foi imprescindível para que os elementos de conversa informais e observações fossem acrescentados ao rol de dados desta pesquisa. 


\section{Processamento e análise dos dados}

Para melhor abarcar o objetivo proposto pelo estudo e melhor apreensão da complexidade do fenômeno do uso de substâncias psicoativas, as compreensões construídas foram realizadas a partir das observações de campo e transcrições das entrevistas, tendo como referência a proposta interpretativa de Clifford Geertz. ${ }^{(20)}$

$\mathrm{Na}$ 'Descrição densa' do que se está fazendo reside o objeto da etnografia, e trata-se de uma organização de estruturas significantes, que orientam os comportamento e sua interpretações. ${ }^{(20)}$ Deste modo, a análise consiste na escolha de estruturas de significação, de “códigos estabelecidos", apontando a sua base social e a sua relevância. Tratando-se a etnografia enquanto uma descrição densa, ${ }^{(20)}$ o pesquisador em sua empreitada investigativa enfrenta, a partir de um emaranhado de estruturas conceituais complexas da vivências dos sujeitos, o desafio de apreendê-las e posteriormente apresentá-las.

Sendo assim, nesta análise, buscou-se conhecer as práticas de uso de SPA, sua organização dentro daquele grupo específico e apreender como estas práticas ocorrem. E, junto aos próprios sujeitos, buscou-se os significados que estes atribuem aos modos como utilizam as SPA, e em que medida práticas de cuidado com a saúde perpassam os usos de psicoativos. Posteriormente, esta prática cultural foi sistematicamente descrita, assim como os significados que lhes foram atribuídos, articulando as interpretações tecidas pelos nativos e por parte das pesquisadoras.

Vale ressaltar que o estudo não corresponde diretamente a tudo que o objeto de estudo representa ${ }^{(20)}$ ou seja, sendo as descrições atravessadas pelo pesquisador (aquele que descreve), elas devem ser tomadas como interpretações deste que se submeteu à experiência, e as expressa na forma de descrição do que está sendo estudado.

A interpretação antropológica pode ser, então, entendida como a construção de uma leitura do que acontece, e ela não deve ser feita distante do contexto onde ocorre, onde as pessoas falam o que fazem, e o que se produz a partir daí, ela conduzirá ao cerne do que se pretende interpretar. ${ }^{(20)}$ Sendo assim, dada a imersão no contexto de uso de substâncias psicoativas, buscou-se explorar o que ocorria nestes cenários, a fim de construir possíveis leituras/interpretações que parte da análise do que é descrito e relatado. As pesquisadoras, ao registrarem sistematicamente suas observações, possibilitaram que os acontecimentos, que 
existem apenas em seu momento específico, estivessem acessíveis e pudessem ser revisitados. ${ }^{(20)}$

Vale notar que não se estuda o lócus especificamente, mas sim no lócus, isto permite pensar com os nativos questões consideradas relevante naquele meio, de forma mais "criativa e imaginativa". ${ }^{(20)}$ Neste estudo, não se perdeu de vista que o que se apreende do contexto deve ser estar pautado, primordialmente, a partir da perspectiva da própria população estudada. Sendo assim, procurou-se refletir acerca de riscos à saúde e possíveis estratégias de cuidado e autocuidado relacionando-os com as práticas destes grupos específicos. O que se descreveu foi uma compreensão a que uma parcela dos informantes nos conduziu, pois não se descreve "o discurso social bruto", o que pode ser acessado/ apreendido é apenas parte de um contexto em que não se é ator. ${ }^{(20)}$

Dito isto, a partir das entrevistas (transcritas) e dos elementos observados durante os seis meses de imersão em campo, que foram registrados no diário, foi realizado uma classificação das entrevistas e dos registros contidos nos diários de campo, tendo como norteador os questionamentos levantados pelos objetivos de pesquisa. Posteriormente, foram construídos quatro eixos temáticos de discussão a partir dos quais se descreveu algumas compreensões acerca do objeto de estudo desta pesquisa.

\section{- Aspectos éticos}

Uma vez que se trata de uma pesquisa que envolve seres humanos, este projeto foi submetido ao Comitê de Ética e Deontologia em Estudos e Pesquisa da (CEDEP) da UNIVASF, e, após a análise e aprovação dessa instância, ${ }^{*}$ deu-se início ao processo de coleta de dados mediante imersão no campo.

No que concerne à realização das entrevistas, estas pressupunham que os participantes fossem previamente informados dos objetivos e finalidades da pesquisa, e que lhes seriam garantidos confidencialidade quanto a sua identidade, através da ocultação de seus nomes, bem como o sigilo de todas as informações coletadas nesta atividade, e que apenas as pesquisadoras responsáveis teriam acesso às informações concedidas por ele.

Foi salientado ao informante que os resultados obtidos seriam utilizados exclusivamente para fins científicos e acadêmicos, incluindo sua publicação em veículos

\footnotetext{
* Protocolo de aprovação nº 0007/170412, CEDEP/ UNIVASF. 
científicos e sua apresentação em congressos, prezando sempre pelo anonimato do participante. E que sua participação teria caráter voluntário, não implicando em nenhum tipo de despesa ou pagamento mediante a participação neste estudo.

Por se tratar de uma "população oculta", que pratica atividades consideradas ilícitas perante a legislação vigente, optou-se por não utilizar a Termo de Consentimento Livre e Esclarecido, pois esta identificação poderia ser encarada, pelos indivíduos, como um risco a sua integridade e como um instrumento de delação das suas práticas ilícitas.

O recorte metodológico desta pesquisa não ofereceu riscos físicos ou psicológicos aos participantes, que, a qualquer tempo, poderia desistir de sua participação sem que isto lhes acarretasse qualquer ônus. Após a análise do material coletado, este trabalho foi disponibilizado para a comunidade acadêmica através da produção de caráter científico. E espera-se que o trabalho contribua com a construção de estratégias de saúde voltadas às pessoas que fazem uso de psicoativos, desassistidos pelos serviços de saúde.

\section{ANÁLISE E DISCUSSÃO DE RESULTADOS}

\section{Eixo I - Padrões de consumo}

Neste estudo foi possível observar um padrão compulsivo ${ }^{(21,4)}$ de consumo de substâncias psicoativas, que é caracterizado por uso violento, sem controle ou limite, repetidas vezes, havendo desconfortos físicos e psicológicos quando o uso é descontinuado. Este padrão é caracterizado por ter frequência e intensidade de uso elevadas, com períodos longos de duração, causando uma certa de dependências psicológica, sendo motivados pelo desejo de obtenção dos efeitos esperados ou por crises de abstinência. ${ }^{(21)}$

Nos contextos pesquisados, tanto o álcool quanto o crack $^{*}$ encontram-se sendo utilizados diariamente de forma intensa, onde o limite é não haver mais substância disponível para consumo ou condições físicas/psicológicas para continuar o uso. É perceptível também que o uso de substâncias psicoativas tornou-se a atividade central na vida da maioria destas pessoas. Muitos deixaram suas casas para habitarem os espaços de rua a fim de adquirir e usar as SPA livremente, passando gradativamente a negligenciar mais e mais a alimentação, higiene pessoal e cuidado geral consigo, tornando prioridade absoluta a aquisição da substância. Como aponta Siegel no padrão de uso compulsivo nota-se a preocupação com aquisição e uso da SPA, enquanto outras dimensões da vida são negligenciadas. ${ }^{(21)}$

\footnotetext{
* Variante fumável da cocaína. 
As temporadas de uso prolongado podem durar 12 horas consecutivas (podendo ser seguido neste mesmo ritmo durante meses), ou durarem 48 horas ou mais de uso intenso, com pausas curtas. Nestes períodos, deixa-se de lado qualquer tipo de cuidado com saúde, incluindo ações básicas como o sono, alimentação e hidratação do corpo e higiene pessoal.

Cansei de fumar 600 conto assim, um dia eu mais Estela* lá de Petrolina, e nisso fumamos 1200 conto, numa noite, agora só vai quem tem coragem”. (Entrevista $5)^{\dagger(22)}$

Tava usando mermo, num vou menti. Passei mais de 20 dia sem comer nada em casa, só na rua e com a roupa só do corpo[...] tomava banho, mas no rio; mas a roupa era a mesma. (Entrevista 6$)^{(22)}$

Os sujeitos desta pesquisa descrevem o álcool e o crack como destrutivos, sendo o crack considerado mais prejudicial. Tal qualificação decorre dos efeitos negativos decorrentes do uso das substâncias: uso exacerbado e sem controle, inibição do apetite e do sono, descuido geral consigo, degradação corpórea, desconfortos em virtude da crise de abstinência em que fissura torna-se mais intensa, fato este que em sua maioria justificam a permanência no uso e/ou a dificuldade de abandono. A fissura é considerada determinante para o estabelecimento deste padrão de uso compulsivo e fracasso na manutenção da abstinência. ${ }^{(23)}$

Aqui pode exterminar uns cinco, vai ter sempre gente vindo pra cá, esse vício é demais. [...] Eu já tive num centro de recuperação, mas a abstinência era demais, não guentei não. (Entrevista 9) ${ }^{(22)}$

A vez que eu parei de fumar crack, eu fiquei doido. Eu saí da roça lá no salitre. Passei o que? Passei mais de 5 dia sumido no mei do mato. (Entrevista 6) ${ }^{(22)}$

Porém, quanto ao uso da maconha não foi identificado um padrão de consumo similar ao álcool e ao crack, ainda que seu uso seja frequente, pois além de sua utilização não ser feita de modo descontrolado, aqueles que os utilizam não descrevem uma relação problemática com a substância, apontando seus efeitos psicoativos sob uma perspectiva positiva. Caracterizando, assim, um uso controlado, que apresenta baixos custos sociais para os sujeitos que a utilizam. ${ }^{(3)}$

\footnotetext{
* Nome fictício.

+ Relato colhido por Geisabel Lima Silveira para o TCC sobre O Consumo de substâncias psicoativas entre pessoas em situação de rua na cidade de Juazeiro-BA (2013), orientado por Luzania Barreto Rodrigues.

* Algumas características da crise de abstinências são desânimo, tristeza, depressão intensa, inquietação e irritabilidade, e iniciam-se pouco tempo após o fim do uso da SPA, produzindo inclusive um desejo inteso de continuação do uso ('fissura') (25)
} 
Só a única droga mesmo que eu uso mesmo direto assim, só é a maconha, só to usando mesmo a maconha. Que a maconha eu já sei que uma maconha assim é uma [...] coisa mais normal, não atinge tanto que nem outras aí, deixa a pessoa meio alucinada. Maconha não, não deixa alucinada maconha, maconha deixa a pessoa mais calmo mais relaxado. (Entrevista 2$)^{(22)}$

Além disso, a maconha também aparece como auxiliando e /ou atenuando os efeitos descritos pelos sujeitos como negativos, causados por outras substâncias psicoativas, como estimulando apetite, sono, amenizando a fissura no crack e diminuindo o desejo de consumir álcool.

Eu digo: "não, meu negócio é cachaça!" e não era nem a maconha mesmo, por que quando eu tava bebendo, eu não usava a maconha não; agora quando eu usava a maconha bebendo, eu já parava de beber mais, já diminuía mais no dia,[...] já diminuía mais que eu me sentia mais calmo. Relaxava mais, aí pronto! E o álcool não. $\mathrm{O}$ álcool deixa o cara mais, quanto mais quer, mais quer beber, mais quer beber, pronto! E a maconha não, relaxava. Dava vontade de ir em casa, tomava um banho, já almoçava, já bebia, quando era de tarde vinha, aí bebia de novo, mas já não bebia do jeito que bebia antes não, já bebia mais pouco... mais moderadamente. $\left(\right.$ Entrevista 2) ${ }^{(22)}$

Esta forma de uso pode caracterizar um padrão circunstancial-situacional que tem a autorregulação como característica. Este padrão de uso varia na constância, intensidade e duração, sendo muitas vezes motivados pela expectativa de alcançar o efeito específico de uma SPA familiar ao sujeito, com vistas a obter auxílio em situação problemáticas, ou de outra ordem, inclui-se também o uso recreativo. ${ }^{(21)}$ Conforme o mesmo autor isso esta forma de uso pode ocorrer numa frequência de mais de três vezes por dia.

\section{Eixo II - Contextos e forma de uso}

Neste tópico, serão apresentados os contextos e formas de utilização de SPA. Observou-se nesta pesquisa que cada localidade específica tem uma dinâmica particular de funcionamento. No geral, nota-se que cada localidade tem a predominância de uma substância psicoativa, enquanto outras substâncias aparecem sendo utilizadas de modo secundário ou complementar.

A localidade "Arena", em que há predominância do uso de crack, fica na região central da cidade. Trata-se de um espaço aberto em que há ampla visibilidade tanto daqueles que nele permanecem com intuito de usar e/ou vender SPA quanto dos transeuntes, o que também torna comum as investidas policiais com vistas a repreender as práticas de uso e

\footnotetext{
* Nome fictício.
} 
comércio. Existem bares e restaurantes nas imediações desta localidade, onde se adquirem álcool e cigarros, e parece haver doação de alimentos de alguns estabelecimentos comerciais.

Pode-se observar um fluxo intenso de pessoas (homens, mulheres e crianças), pois este é um ponto de venda e uso da referida substância. Parte dos que estão alocados nesta região abandonou seus lares - por vezes temporariamente - e, nestes casos, desenvolvem trabalhos alternativos nas imediações. São comuns lavagem de carros, prostituição e disponibilização da mão-de-obra para pequenos serviços em estabelecimentos comerciais, sendo estas algumas fontes de renda para manutenção do consumo da substância. Desse modo, esta localidade figura como contexto de trabalho, aquisição, consumo e repouso para algumas pessoas. Notase também que a utilização da substância tornou-se atividade central na vivência de muitos destes sujeitos, que fazem uso compulsivo e sem controle.

A utilização do crack neste contexto é feita coletivamente, no qual se reúnem cerca de três ou seis pessoas, no máximo, dividindo tanto a substância quando os instrumentos para a sua utilização. Ainda que não represente a maioria, também foram observadas pessoas que utilizam a substâncias sozinhas. Nestes casos, poucos deles possuem cachimbos como instrumento pessoal de uso, acessando-os por empréstimo, ou utilizando latas de alumínio que são facilmente encontradas.

O crack é, exclusivamente, fumado, embora haja uma diversidade de formas de utilização. O modo mais comum de uso do crack é em cachimbos. Estes instrumentos são confeccionados a partir de materiais como: canos de PVC, antenas de TV, tampinhas plásticas $^{*}$ e torneiras de metal. Após a confecção do cachimbo, monta-se uma grelha de suporte para o crack, cobrindo o fornilho com papel alumínio, vedando as laterais com plástico e fazendo buracos no papel para dar passagem à fumaça. Para que seja possível efetuar a combustão da "pedra de crack", é necessário colocar cinza de cigarro para que a mesma aqueça a SPA até a combustão, e assim possa ser aspirada.

Entre os sujeitos que utilizam o cachimbo, também se observou a prática de extração da "borra", que consiste em reutilizar os resíduos que ficam depositados no cachimbo após o uso do crack. Segundo relato de um colaborador desta pesquisa, é uma espécie de óleo e, para realizar este processo, é necessário lavar o cachimbo com álcool, de modo que a substância

\footnotetext{
* Foram citadas tampas de bastões de brilho labial, garrafas PET e frascos de esmalte, que são utilizadas para confecção do fornilho do cachimbo.

† As cinzas são os resíduos que sobram da queima do cigarro de nicotina, cuidadosamente coletados e reservados para esta finalidade. Este processo é necessário, pois "o crack" não entra em combustão apenas em contato direto com o fogo.
} 
misture-se a este. Após esta limpeza, despeja-se o conteúdo no fundo da lata* ${ }^{*}$ queima-se a mistura de álcool e resina, restando apenas o que se denomina como "borra", uma substância escura e pastosa (quando ainda quente), que será fumada novamente.

O crack também pode ser utilizado na forma de cigarro. Utiliza-se o conteúdo do cigarro de nicotina (ainda não fumado) misturado às "pedras de crack". Em seguida, enrola-se em papel apropriado para formar um cigarro. Este mesmo procedimento é utilizado para confeccionar pitílho, ${ }^{\dagger}$ que substitui o tabaco pela cannabis sativa, produzindo também um tipo de cigarro. O pitilho também pode ser utilizado em cachimbos.

O crack também é fumado em latas de alumínio. É comum amassar a parte lateral da lata formando uma cavidade, de modo que a SPA possa ser ali colocada. No centro desta cavidade, são feitos pequenos buracos e sobre estes são colocadas as "pedras de crack" e as cinzas de cigarro, onde será realizada a combustão. A fumaça é aspirada pelo orifício superior da lata. A opção pelo uso de latas de alumínio reside no fato de que portar um cachimbo é um elemento delator do consumo de crack, enquanto o mesmo não se aplica a este utensílio, que pode ser facilmente encontrado, utilizado e logo descartado.

Na Feira-Livre, é predominante o uso de álcool, o que não exclui o uso adicional de outras SPA. Há um grupo pouco variável de pessoas que frequenta esta localidade diariamente e que utiliza o espaço como local de trabalho, moradia e uso e abuso de SPA. Nesta Feira-Livre, os indivíduos pertencentes ao grupo estudado realizam atividades laborais de carga e descarga de caminhões, para estabelecimentos comerciais dos arredores. A renda adquirida é utilizada para aquisição da substância e raras vezes para aquisição de alimentos. Estes, em sua maioria, são arrecadados junto à família ou no comércio, e trazidos para serem divididos com o grupo. A maioria dos sujeitos acessados durante a pesquisa relata retonar para casa durante a noite, mas há aqueles que residam neste espaço. É comum, inclusive entre os que têm moradia fixa, dormirem no local durante a noite.

Nesta Feira-Livre, o uso abusivo de SPA, seja o álcool ou outras substâncias (crack, cigarro de nicotina e cannabis sativa) configura a cena social e ordena o cotidiano dos indivíduos. Em sua maioria, são utilizadas substâncias psicoativas cujo teor alcoólico é de aproximadamente $39 \%$, “cachaças e bebidas quentes", como é comum entre a população

\footnotetext{
* Corta-se o fundo da lata e utiliza-se a parte côncava como recipiente onde será despejada a mistura de álcool com os resíduos de crack já fumado.

† Ou pití. São termos utilizados pelos sujeitos entrevistados para referenciar o uso combinado de crack e maconha.
} 
pesquisada referir-se a essas substâncias. O uso é feito coletivamente. Reúnem-se em média seis a oito pessoas, todas do sexo masculino*. É comum que a garrafa fique localizada no centro da roda ou à vista de todos e cada um vá se servindo em doses. Coloca-se a quantidade desejada em um copo e ingere-se de uma só vez, de modo a disponibilizar o copo para que outra pessoa também possa utilizá-lo. Não é comum que cada sujeito tenha o seu utensílio, o mesmo é compartilhado por todos na roda.

Ali, percebe-se descuido com saúde, com a alimentação e a higiene pessoal. Observaram-se relatos de pessoas doentes e/ou com ferimentos que mostravam relutância em buscar os serviços de saúde. O que faziam apenas em casos de crises severas de abstinências, com episódios de alucinações e delírios, ou outros casos graves.

Em ambos os contextos, observou-se uma forma cooperativa entre aqueles que utilizam tanto crack quanto álcool, no que concerne à aquisição da SPA. É comum a pessoa que adquire, por exemplo, uma "pedra de crack", convide um ou mais colegas para dividirem "o peguinha" ${ }^{\dagger}$ bem com os instrumentos de uso. Assim, quando o sujeito que ofertou a SPA não dispunha de utensílio para o próprio consumo, outros a disponibilizavam. Do mesmo modo, acontecia nas rodas de uso de álcool. Todos colaboram para manter o suprimento da substância psicoativa disponível ao grupo.

Durante o período de realização da presente pesquisa, notou-se uma forte repressão policial em todos os contextos de uso de substância psicoativa, e principalmente nos espaços de uso de crack. Sendo assim, algumas estratégias para a ocultação da SPA - como escondêla na boca -, bem como o cuidado de não portar cachimbo foram criados e observados, com intuito de evitar conflitos com a lei. Desse modo, os contextos de uso parecem estar intrinsecamente relacionados com adoção de práticas que oferecem riscos aos sujeitos.

\section{Eixo III - Risco e danos à saúde}

Entre os riscos e danos à saúde observados nesta pesquisa, pode-se inferir que uma parcela destes é objeto de atenção e cuidado por parte dos sujeitos entrevistados, enquanto outras ficam negligenciadas ou ainda não são discursivamente identificados como danosos à saúde. Dentre os riscos à saúde identificados por eles, aos quais são despendidos atenção e cuidado, cita-se primeiramente o de exposição às Doenças Sexualmente Transmissíveis. Os

\footnotetext{
"Não é comum a presença de mulheres nesta localidade.

† Formas como os sujeitos que utilizam crack, se referem às pequenas porções da substância. 
entrevistados demonstram que adotam práticas para evitar o risco de contrair doenças, principalmente através do uso de preservativo.

Eu vou pra um programa c'uma menina, eu não vou sair com ela sem camisinha, tá me entendendo ? (Entrevista 5)

Assim, me cuido muito bem, por exemplo, as camisinhas uso sempre, não deixei de usar, gosto de usar, sabe?! Eu sou uma pessoa muito cuidadosa, gosto muito de mim principalmente, né?! (Entrevista 7) ${ }^{(22)}$

O uso de substâncias psicoativas pode contribuir para que práticas inseguras sejam mais frequentes, sobretudo, considerando-se que a prática sexual nesses contextos tornou-se fonte de renda e/ou moeda de troca para aquisição de substâncias psicoativas, principalmente o crack. Sendo assim, os riscos de contaminação parecem altos, o que aponta para a relevância da adoção de práticas preventivas.

Alguns fatores de risco são apontados exclusivamente pelos sujeitos que fazem uso de crack, o primeiro deles é a possibilidade de overdose, em virtude do consumo de grandes quantidades da substância. Os entrevistados não relatam ter vivenciado essa experiência, porém apontam estratégias a fim de evitar complicações similares, uma vez que testemunharam pessoas do círculo de uso que apresentaram sintomas agravantes em decorrência do uso do crack.

Eu acho assim, que pra se usar uma droga você tem que ter uma boa alimentação, sabe?! Tem que tá preparado. E eu vejo muitos aqui... já salvei dois aqui. [...] De overdose, cair no chão e ficarem olhando e não ajudarem, tá entendendo? E eu chegar e ajudar. Vi dois mesmo já vi um espumando quase morrendo mesmo. $\left(\right.$ Entrevista 7) ${ }^{(22)}$

Problemas respiratórios decorrentes do uso do crack também são identificados pelos sujeitos desta pesquisa como causa de danos à saúde, pois são frequentes episódios de tosse, rouquidão, cinzas expelidas nos escarros, dores no peito. É perceptível que as formas de utilização desta substância contribuem diretamente para a contração destas doenças. Desse modo, uma parcela dos sujeitos entrevistados busca produzir instrumentos atentando para o aumento ou diminuição da ingestão de partículas sólidas.

Eu mesmo faço! Pego o alumínio, de marmiteque, furo um buraquinho pequeno pra não passar a cinza, na hora do pulmão. Com o buraco grande a cinza passa; a cinza já é queimada e eu vou queimar ela de novo, e ai? Tô me prejudicando. (Entrevista $5)^{(22)}$ 
A factualidade dos danos respiratórios causados pelo fumo de crack, através da ingestão de partículas, e em virtude das altas temperaturas ao qual o pulmão é exposto. ${ }^{(11,24)}$ Discursivamente, alguns comportamentos são sinalizados pelos sujeitos desta pesquisa como potenciais causadores de danos à saúde. Porém, pode-se observar que, na prática, estes ainda não são objeto de cuidado contínuo da população estudada. O hábito de evitar o compartilhamento dos instrumentos para a utilização de substâncias psicoativas é de difícil incorporação por parte dos sujeitos objeto desta observação. Por exemplo, numa rodada de uso de crack, entre três ou mais pessoas, o mesmo cachimbo é utilizado por todos que estejam participando da atividade.

\begin{abstract}
Bom, a partir do momento que aquela pessoa usa uma coisa nova é um uso saudável, mas na hora que passa na boca de outra pessoa já não é. E, na hora que eles estão fumando, eles não lembram disso. Se você disse que vai dar um pedaço a alguém, pra emprestar uma lata ou um cachimbo, dá! Entendeu?! (Entrevista 8) ${ }^{(22)}$
\end{abstract}

Isso também se aplica aos sujeitos entrevistados que fazem uso de álcool, que compartilham copos, latas e garrafas. Porém, aqueles que fazem uso de crack apresentam fatores agravantes, pois o uso do crack em cachimbos, em muitos casos, inclusive nos observados em campo, causa queimaduras e ferimentos, com sangramento nos lábios, elevando os riscos de transmissão de vírus e doenças como HIV, hepatites, tuberculose e herpes. ${ }^{(11)}$

Dentre as práticas prejudiciais à saúde, está o descuido com a alimentação, com o sono e com a higiene pessoal, nos períodos prolongados de uso de crack e/ou álcool* . O crack, principalmente por ser uma substância estimulante, tem entre os seus efeitos a inibição do apetite e do sono. Em virtude disto, leva o indivíduo à desnutrição, desidratação e gastrite, ocasionando perda considerável de peso e debilidade física ${ }^{(11,24)}$.

Quando a pessoa tá usando, que a pessoa vai comer, a pessoa faz é vomitar de novo. $\left(\right.$ Entrevista 3) ${ }^{(22)}$

Se eu usar o crack eu passo 2,3 dias sem dormir e sem comer. (Entrevista 5) ${ }^{(22)}$

Rapaz, comigo mesmo tem dias, muitos dias que eu... tem hora que eu nem durmo, quando eu durmo, se jogo na praça mesmo, banho é difícil, só quando eu venho paí pro rio mesmo [...] Lavagem das roupas é quando eu vou nas casa, ai eu peço uma... peço roupas às pessoa e jogo fora as vea.( Entrevista 3$)^{(22)}$

\footnotetext{
* As temporadas de uso prolongado podem durar 12 horas diárias (podendo ser seguido neste mesmo ritmo durante meses), ou durarem 48 horas ou mais de uso intenso, com pausas curtas, como apontado no EIXO I. 
Eu tava tanto no vício, tanto bebendo direto aí que nem me alimentar direito eu tava me alimentando, eu chegava em casa não colocaria 3,4 , colher de comida na minha boca, eu colocava pronto, já tava voltando, não descia. Aí eu comia um pedaço de doce às vezes, aí voltava e vinha beber de novo, e me tremendo que é ruim demais a pessoa; a pessoa que não se alimenta, tem outros tem outros que se alimenta, mas tem outros muitos que não se alimenta. Aí onde vem e dá a fraqueza. (Entrevista 2) (22)

A utilização do crack em latas de alumínio não é vista pelos sujeitos desta pesquisa como um dos fatores que podem oferecer riscos à saúde, uma vez que não há uma preocupação com a procedência dos materiais, os quais muitas vezes são coletados nas ruas e nas lixeiras, e não há cuidado de fazer limpezas, ou algo neste sentido.

Optar pela prática de uso da substância psicoativa neste tipo de instrumento, o sujeito acaba aumentando o risco de contaminação por diversas doenças, ${ }^{(11)}$ aí incluídos os problemas respiratórios, uma vez que os orifícios feitos na lata passam uma maior quantidade de cinzas.

Outros danos estão associados ao uso do crack em latas de alumínio. Estudos realizados no Rio Grande do Sul apontam que enfraquecimento dos ossos, demência e agravamento do Mal de Alzheimer são efeitos da exposição ao alumínio em virtude do seu aquecimento. ${ }^{(11)}$

Uma prática que também expõe as pessoas que utilizam crack a riscos decorrentes do consumo adicional de alumínio é a raspagem do fundo das latas durante o processo de extração da "borra", uma vez que o alumínio acaba misturando-se à "borra", que será queimada e inalada, aumentando, assim, a possibilidade de danos à saúde. Outro fator agravante é que esta prática acaba agregando, também, a parcela dos indivíduos que utilizam exclusivamente os cachimbos, pois estes, apesar de não fumarem diretamente na lata, a insere no seu circuito de uso no processo de extração da "borra". Além disso, a prática da 'raspagem' também é feita nos próprios cachimbos, para retirada dos resíduos de crack já fumados. Dessa forma, pequenas partículas de PVC também são misturadas à 'borra' e posteriormente fumadas, representando mais um fator de risco à saúde dessas pessoas.

Dentre os fatores já citados, referentes ao risco à saúde decorrente da utilização da "borra", outro aspecto a ser assinalado é que o hábito de "limpar" o cachimbo para extrair a "borra" fomenta a prática de compartilhamento do instrumento de uso. Isto porque, quanto mais o cachimbo for utilizado, mais resíduos ficarão depositados no recipiente, de modo que, quando a limpeza vier a ser feita, o dono do cachimbo terá uma "fumada a mais". Sendo

\footnotetext{
* Conforme assinalado no Eixo 2.
} 
assim, as pessoas costumam emprestar seus cachimbos aos demais, como via de aquisição de resíduos, aumentando o risco de transmissão de doenças.

Em virtude da repressão policial nas localidades de uso de crack, tornou-se frequente, entre os sujeitos acessados por essa pesquisa, a prática de ocultar "petecas" "* escondendo-as na boca. O mesmo acontece com os pequenos traficantes. Segundo relato de uma entrevistada, o crack corrói a parte inferior da unha: "chega fica na carne" (sic). Quando colocada no dente, o mesmo enfraquece e logo quebra, o que também causa ferimento na língua. Desse modo, pode-se inferir que o contexto social no qual tais sujeitos se encontram acabou influenciando o desenvolvimento de uma prática que tem oferecido riscos de contaminação e transmissão de doenças.

\section{Eixo IV - Possibilidade de cuidado à saúde}

Algumas práticas foram apontadas pelos sujeitos como estratégias de minimização de risco e danos à saúde. O uso do preservativo foi colocado pelos sujeitos como uma estratégia de cuidado à saúde. De acordo com seus relatos, esta é uma prática adotada e utilizada com frequência, com intuito de evitar o risco de transmissão de Doenças Sexualmente Transmissíveis (DST).

Nos cachimbos de crack, uma das estratégias adotadas é a utilização de materiais finos para construção dos cabos que conduzem a fumaça até à boca, pois dificultam a passagem de resíduos sólidos, diminuindo os desconfortos em virtude da ingestão de cinzas. Os materiais mais comuns utilizados para fabricação deste tipo de instrumento é a antena de televisão e torneiras metálicas utilizadas em filtros.

Sabe-se que para fumar o crack é necessário queimá-lo. Para tanto, é necessário, além de utilizar a cinza de cigarro para efetuar a combustão, cobrir o fornilho do cachimbo com papel alumínio e realizar perfurações para dar passagem à fumaça. Os sujeitos dessa pesquisa sinalizam que orifícios grandes dão vazão a uma quantidade maior de cinza e fumaça, prática que aumenta a incidência de problemas no trato respiratório. Percebeu-se que parcela desta população adotou a prática de confeccionar buracos pequenos, utilizando preferencialmente a parte pontiaguda de palitos de dente, com vistas à diminuição da ingestão de partículas

\footnotetext{
* Embrulho plástico que envolve a pedra de crack.
} 
sólidas. Deste modo, evitar o uso da substância em latas de alumínio também representa uma estratégia para evitar problemas similares.

Outra prática sinalizada por parte dos sujeitos acessados por esta pesquisa, para evitar desconfortos no sistema respiratório, é a utilização de pedaços de fraldas de pano, que são acoplados à piteira onde a fumaça é aspirada, obstruindo a passagem de partículas sólidas. A opção pela utilização de fraldas é que o tecido funciona como um filtro, impedindo a passagem de resíduos, sem comprometer a passagem da fumaça.

Entre a população que faz uso de crack, outra estratégia para evitar risco e danos à saúde é a divisão/quebra das "pedras" em pequenas porções para um uso gradativo, com vistas a evitar desconfortos físicos, agravos à saúde ou overdoses.

Os sujeitos desta pesquisa que fazem uso de álcool e/ou crack relatam usar maconha, em virtude dos seus efeitos positivos: estimula fome em situações de falta de apetite, que são frequentes no período de uso de substâncias psicoativas excitatórias do Sistema Nervoso Central; diminui a dificuldade para dormir, ameniza a fissura por crack e atenua o desejo de uso do álcool. Parte dos sujeitos desta pesquisa estabelece como meta o abandono das demais substâncias psicoativas e a utilização exclusiva da cannabis sativa, por considerarem esta a substância menos prejudicial à saúde. O pitilho também se insere nesta instância, pois é utilizado com intuito de amenizar os efeitos do crack. Os sujeitos entrevistados afirmam que a intensa ansiedade causada pelo crack é amenizada pelos efeitos produzidos pela cannabis, auxiliando inclusive na diminuição da fissura, ou seja, o forte desejo de consumir repetidamente o crack.

Uma estratégia adotada por pessoas que fazem uso tanto do crack quanto do álcool é eleger períodos de abstinências. Nestes períodos de interrupção do uso, alguns desses sujeitos preferem distanciar-se dos cenários de utilização, pois estes estimulariam o consumo. Muitos voltam para seus lares e passam uma temporada, com intuito de recuperar-se do intenso desgaste físico e mental provocado pela substância, retomando cuidado com a alimentação, higiene pessoal e o sono. Ao retornarem aos contextos de uso de SPA, a diferença positiva na sua compleição física é sempre notória. Também é comum nestes períodos que haja suspensão apenas da substância considerada mais prejudicial, mantendo o uso de outras consideradas mais "leves", a exemplo da maconha e o cigarro de nicotina.

As estratégias apresentadas a seguir são visualizadas pelos sujeitos desta pesquisa como possíveis de se inserem nos contextos de uso, porém estas ainda não foram adotadas, 
fazendo parte apenas dos seus discursos. O uso compartilhado de instrumentos para utilização de substâncias psicoativas é reconhecido pelos sujeitos como uma prática que oferece risco à saúde. Porém, observou-se que há uma grande dificuldade em ser colocada em prática em todos os contextos observados. Isto se aplica também aos cuidados com a alimentação, higiene pessoal e sono.

Nesta pesquisa, ficou perceptível que a suspensão total do uso da substância psicoativa é apontada pela maioria dos sujeitos da pesquisa como a única via de se restabelecer a saúde. Disso resulta ser muito comum apontarem as instituições pautadas na abstinência como uma possibilidade de cuidarem da saúde. Porém não se observou qualquer iniciativa neste sentido, nem relatos exitosos.

De modo geral, é escassa a busca pelos serviços de saúde institucionalizados da rede municipal de saúde. Porém, entre aqueles tiveram algum contato, as principais alegações para não utilizarem esses dispositivos é o excesso de burocratização, recorrendo a estes apenas em casos de agravos extremos à saúde.

\section{CONSIDERAÇÕES FINAIS}

Este estudo ratifica o fato de que a população em situação de rua na cidade de Juazeiro-Ba encontra-se desassistida e desamparada pelas políticas assistenciais à saúde para pessoas que fazem uso de substâncias psicoativas. Isto aponta a necessidade de ações específicas voltadas a este público, tendo em vista que se evidenciou neste trabalho que as formas, as práticas e os contextos de uso de Substâncias Psicoativas estão oferecendo riscos à saúde desta população.

Foi possível verificar que, ainda que de modo incipiente, práticas de autocuidado com a saúde brotam naqueles contextos, convocando, assim, os profissionais de saúde a apropriarem-se deste fenômeno que se revela desafiador, um campo fértil para intervenções. A imersão neste campo nos coloca frente ao paradigma da construção de práticas terapêuticas que não esteja restrita os "settings clínicos" tradicionais, bem como com a ruptura com modos de cuidado massificados e homogeneizadores.

Ao se inserir nestes contextos, é crucial ao profissional de saúde uma atuação criativa e singularizante, favorecendo que o sujeito resgate o seu potencial atuante e inventivo frente ao processo de (re)construção do cuidado de si. Cabe, também a tais profissionais, elaborar 
novos sentidos frente ao seu modo de relacionar-se com os sujeitos que fazem uso de SPA, buscando criar ações/intervenções inéditas, contextualizadas e palpáveis para minimizar os danos e prejuízos à sua saúde da população em apreço e sua vivência em sociedade, em decorrência do uso de SPA. Para tanto, é preciso romper, inclusive, com antigas classificações e enquadres que ocultam, silenciam e mortificam o que há de singular no sujeito, rotulando-o e estigmatizando-o, classificando-o e apagando o que há de particular ao sujeito para inseri-lo numa "massa". (12)

Os achados deste trabalho nos fornecem algumas informações valiosas sobre um panorama do cenário do uso de SPA nos contextos de rua da cidade de Juazeiro-Ba e coloca à disposição da comunidade acadêmica esboços de possíveis estratégias de autocuidado com a saúde, criadas a partir das experiências dos sujeitos acessados por esta pesquisa. Estas podem servir de subsídio para futuras intervenções em contextos como este.

Nesta direção, é primordial assinalar que foram observados casos pontuais de sujeitos que afirmam ter alcançado um padrão moderado/esporádico de uso de crack, o que aponta para a necessidade e relevância da realização de novos estudos, cujo enfoque venha contribuir com a compreensão e desmistificação deste fenômeno. Bem como o oposto, através de estudos voltados para construir entendimento acerca dos fatores que influenciam a instalação de padrões de uso compulsivos de SPA, como os encontrados nesta pesquisa.

\section{REFERÊNCIAS}

1. Costa P. População em situação de rua: contextualização e caracterização. Revista Virtual Textos \& Contextos [periódicos na internet]. 2005 [acesso em: 17 out. 2011]; 4(4): 1-15. Disponível em: http://revistaseletronicas.pucrs.br/ojs/index.php/fass/article/viewFile/993/773

2. Ministério da Saúde, Coordenação Nacional de Saúde Mental. Consultórios de Rua do SUS. Material de trabalho para a II Oficina Nacional de Consultórios de Rua do SUS. Brasília: Ministério da Saúde/EPJN-FIOCRUZ; 2010. 48 p.

3. MacRae E, Simões JA. A subcultura da maconha, seus valores e rituais entre setores socialmente integrados. In: Baptista M, Cruz, MS, Matias R, organizadores. Drogas e PósModernidade: faces de um tema proscrito. Rio de Janeiro: Ed UERJ; 2003. p. 95-108.

4. MacRae E. A desatenção da legislação de entorpecentes pela complexidade da questão. Núcleo de Estudos Interdisciplinares sobre Psicoativos. [internet]. 1996. [acesso em: 19 ago. 2011] Disponível em: http://www.neip.info/downloads/t_edw1.pdf 
5. Zoboli E. Cuidado: práxis responsável de uma cidadania moral Elma. In: Pinheiro R, Mattos RA. Razões públicas para a integralidade em saúde: o cuidado como valor. Rio de Janeiro: IMS/ UERJ; 2009. p. 63-78.

6. Oliveira MGPN. Consultório de rua: relato de uma experiência [dissertação]. Salvador: Universidade Federal da Bahia; 2009.

7. Bub MBC, Medrano C, Silva CD, Wink S, Liss PE, Santos EKA. A noção de cuidado de si mesmo e o conceito de autocuidado na enfermagem. Texto \& Contexto - Enfermagem. 2006; (15):152-7. DOI:10.1590/S0104-07072006000500018.

8. Moraes M. Modelo de atenção integral a saúde para tratamento de problemas decorrentes do uso de álcool e outras drogas: percepções de usuários, acompanhantes e profissionais. Ciência e Saúde Coletiva. 2008; 13(1): 121-133.

9. Oliveira GN. O Projeto Terapêutico Singular. In: Campos GWS, Guerrero AVP, organizadores. Manual de práticas da atenção básica: saúde ampliada e compartilhada. 2. ed. São Paulo: Editora Hucitec; 2010. p. 273-288.

10. Brasil CS. A perspectiva da redução de danos com usuários de drogas: um olhar sobre os modos éticos de existência [dissertação]. Porto Alegre: Universidade Federal do Rio Grande do Sul; 2003. [acesso em 5 abr 2013]. Disponível em: http://www.bibliotecadigital.ufrgs.br/da.php?nrb=000462878\&loc $=2005 \& \mathrm{l}=12 \mathrm{c} 44 \mathrm{c} 7 \mathrm{~b} 40 \mathrm{~b} 8 \mathrm{ef}$ $6 f$

${ }^{11 .}$ Domanico A. Craqueiros e cracados: Bem vindo ao mundo dos nóias! - Estudo sobre a implementação de estratégias de redução de danos para usuários de crack nos cinco projetospiloto do Brasil [tese]. Salvador: Universidade Federal da Bahia; 2006.

12. Guerra AMC, Garcia C, Barros FO. Como Viver Juntos? Fronteiras e territórios. Curinga. 2007; (25): 33-37.

13. Amarante P. A (clínica) e a Reforma Psiquiátrica. In: Amarante P, coordenador. Archivos de Saúde Mental e Atenção Psicossocial. Rio de Janeiro: FIOCRUZ, 2008. p. 61-80.

14. Brasil. Ministério da Saúde. A Política do Ministério da Saúde para atenção integral a usuários de álcool e outras drogas. Brasília: Secretaria Executiva, Coordenação Nacional DST/AIDS; 2004.

15. MacRae E, Vidal SS. A Resolução 196/96 e a imposição do modelo biomédico na pesquisa social: dilemas éticos e metodológicos do antropólogo pesquisando o uso de substâncias psicoativas. Revista de Antropologia. 2006; 49(2):645-66.

16. Minayo MCS. Pesquisa social: teoria, método e criatividade. 11. ed. São Paulo: Vozes, 1999.

17. Becker HS. Métodos de pesquisa em Ciências Sociais. Tradução de Marco Estevão. 4. ed. São Paulo: Editora Hucitec; 1999. 
18. MacRae E. Abordagens qualitativas na compreensão do uso de psicoativos. In: Tavares LA, Almeida ARB, Nery Filho A, organizadores. Drogas: tempos, lugares e olhares sobre seu consumo. Salvador: Edufba; 2004. p. 27-48.

19. Minayo MCS. O desafio do conhecimento: pesquisa qualitativa em saúde. 8. ed. São Paulo: Hucitec; 2004.

20. Geertz C. A interpretação das culturas. 1.ed., 13.reimpr. Rio de Janeiro: LCT; 2008. Capítulo 1, Uma descrição densa: por uma Teoria Interpretativa da Cultura; p. 1 - 24.

21. Siegel RK. New Patterns of Cocaine Use: Changing Doses and Routes. In: Kozel NJ, Adams EH, editors. Cocaine Use in America: Epidemiologic and Clinical Perspectives. Rockville, Maryland: NIDA; 1985. p. 204-22. (NIDA Research Monograph 61). [acesso em 18 de mar. 2013] Disponível em: http://archives.drugabuse.gov/pdf/monographs/61.pdf

22. Silveira GL. O Consumo de substâncias psicoativas entre pessoas em situação de rua na cidade de Juazeiro-BA [trabalho de conclusão de curso]. Petrolina: Universidade Federal do Vale do São Francisco; 2013.

23. Chaves TV, Sanchez ZM, Ribeiro L A, Nappo SA. Fissura por crack: comportamentos e estratégias de controle de usuários e exusuários. Rev. saúde pública. 2011; 45(6): 1168-75. DOI: $10.1590 / \mathrm{S} 0034-89102011005000066$

24. Dualibi LB, Ribeiro M, Laranjeira R. Profile of cocaine and crack users in Brazil. Cad saúde pública. 2008 (24); Suppl 4: S545-S57. DOI:10.1590/S0102-311X2008001600007

25. Cruz MS, Vargens RW, Ramôa ML. Crack: uma abordagem multidisciplinar. In: Prevenção ao uso indevido de drogas: capacitação para conselheiros e lideranças Comunitárias. $4^{a}$ ed. Brasília: Ministério da Justiça. Secretaria Nacional de Políticas sobre Drogas; 2011. 